
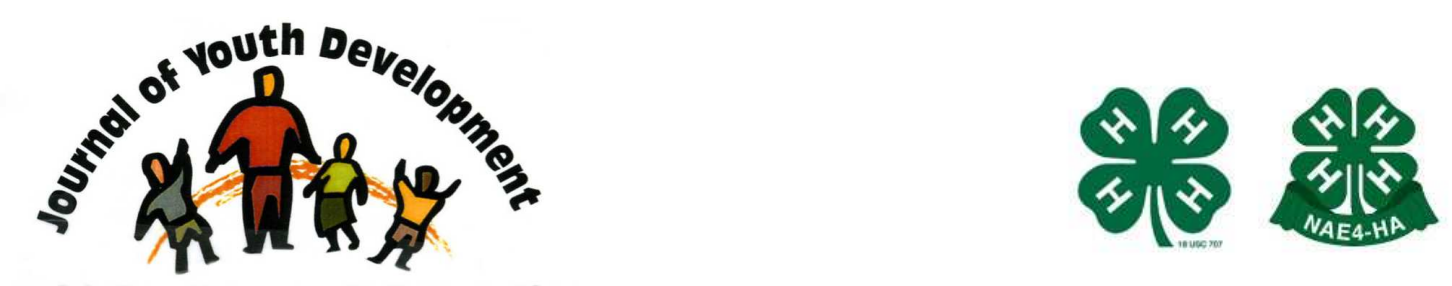

Bridging Research \& Practice

\title{
Purpose and Spirituality: Exploring the Role of Fidelity in Diverse Adolescents
}

\author{
Drew Carr \\ Fuller Theological Seminary \\ Pamela Ebstyne King \\ Fuller Theological Seminary \\ Adrienne Maddix Meier \\ Fuller Theological Seminary
}




\title{
JOURNAL OF YOUTH DEVELOPMENT \\ bridging research and practice

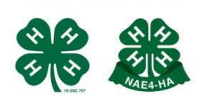

Volume 9, Number 2, Summer 2014

Article 140902FA001

\section{Purpose and Spirituality: \\ Exploring the Role of Fidelity in Diverse Adolescents}

\author{
Drew Carr, Pamela Ebstyne King, and Adrienne Maddix Meier \\ Fuller Theological Seminary
}

\begin{abstract}
Purpose is understood to reflect young people's stable and generalized commitments to accomplish meaningful activity and contribute productively to society. Religion has been linked with purpose; however, the nature of this relationship is not well understood. Given that purpose and religion involve beliefs and devotion, the current study examined fidelity as a means of understanding this relationship in a group of religiously and culturally diverse youth from around the world. The participants were 30 adolescents aged $12-21$ ( $M=17.73$ years) nominated for living with profound spirituality in their community. Consensual qualitative research (CQR) strategies were used. Analysis revealed that 29 of the participants reported a sense of purpose and all 30 participants described some aspect of fidelity that involved (a) beliefs, (b) values, (c) morals, and (d) resolute commitment. These findings highlight the centrality of fidelity as a link between religion and purpose among diverse youth. Future directions for research and practice are discussed.
\end{abstract}

\section{Introduction}

Questions about the relationship between purpose and religion are not new themes within human history. Religious tenets, such as The Four Noble Truths and the Ten Commandments, focus on moral behavior and create meaning within their adherents' lives. Philosophers, theologians, and laity alike have wrestled with how religious beliefs interact with purpose. In recent history, both purpose and religion have garnered theoretical and empirical attention from developmental scientists because each has been suggested to alter the developmental trajectory of youth (e.g., Bronk, Hill, Lapsley, Talib, \& Holmes, 2009; Damon, 2008; King, 2008). Further efforts have sought to understand the relationship between purpose and religion (e.g., Mariano, \& Damon, 2008); however, the link remains unclear. Based on recent findings in a study on adolescent spiritual exemplars (King, Clardy, \& Ramos, 2014), this qualitative study analyzed transcripts of the exemplars to examine how fidelity might illuminate the relationship between religion and purpose in culturally and religiously diverse youth. 


\section{Fidelity}

Adolescence has been suggested to be a time of identity development as well as social and community engagement (Erikson, 1964). Many young people's intentional and unintentional strivings and behaviors focus on seeking a sense of self-understanding (Damon, Menon, \& Bronk, 2003; King, 2008). Through this search, adolescents pose existential questions that orient them towards a quest for meaning and purpose (Damon et al., 2003; Markstrom, 1999) and a sense of how they are related to systems and entities beyond themselves (Lerner, Dowling, \& Anderson, 2003). Thus, the clarity of and devotion to these beliefs appear to be instrumental in the quest for purpose.

Although the concept of fidelity has been present within the developmental literature for decades (e.g. Erikson, 1964), it is often overlooked, and with few exceptions, has not been well developed conceptually or explored empirically. Erikson (1964) argued that fidelity is the basic virtue that results from the successful resolution of the identity crisis and defined fidelity as "the ability to sustain loyalties freely pledged in spite of the inevitability contradictions of value systems" (p. 125). Thus, fidelity refers to clarity about one's beliefs and having a devotion to them. Fidelity is the cornerstone to an adolescents' identity, as it represents an anchoring to a specific social group and an embodiment of the values representative of that community (King et al., 2014). However, fidelity is not a matter of "blind faith," in that adolescents have not experienced a sense of crisis and have foreclosed their identity prematurely (Markstrom-Adams et al., 1993). Instead, they have wrestled with and chosen to live within the boundary of a specific group, embracing the affiliated ideologies.

Though they are similar, fidelity is more than a mere commitment. When a young person is clear about and committed to their beliefs, values, and morals, they are able to navigate the growing complexities of their lives and choose behaviors that are consistent with their identity, purpose, and emerging goals. Lerner and colleagues (2003) described fidelity as not only an "unflagging commitment to abstract ideas beyond the self" (p. 23) but also a facet of a prosocial identity that enables a young person to contribute to the greater world in a socially appropriate manner. In addition, Côté and Levine (2002) describe an agentic aspect of fidelity, emphasizing the devotion of fidelity motivates people to act consistently with their beliefs. For example, volunteer agencies are suggested to promote sincerity, genuineness, and a sense of duty in relationships when youth internalize the values of those groups (King, et al., 2014; Yates, \& Youniss, 1999). Thus, fidelity is more than an intellectual assent of commitment or a statement of faith; fidelity is internalized, forming thought and guiding behavior (Erikson, 1964). Thus, fidelity is not only a resolute commitment to ideals but profoundly shapes human behavior.

\section{Religion, Spirituality, and Fidelity}

But where does fidelity originate? Often, youth look towards established ideological systems, available through religion, politics, or other grand narratives to define themselves (Damon, \& Hart, 1992; Erikson, 1964). Building on Erikson, King (2008) posited that religion provides rich contexts (a) ideologically, through which youth can be exposed to values; (b) socially, in which those morals and values are embodied in members of a congregation, and (c) transcendent, providing meaning and motivation beyond the mundane of daily life. Thus, religion provides a worldview-consisting of values, morals, and beliefs-through which adolescents transcend and understand themselves and the world (Erikson, 1964). As such, an important potential source of clarity and commitment to an ideology is derived from religion. 
Furthermore, Erikson (1964) asserted that religion has the potential to give adolescents purpose in life, confirm identity, and foster a sense of belonging. This is likely due to the social-historical framework religion provides that connects adolescents to traditions and communities (Erikson, 1964). Research has shown that the socialization process of religion facilitates the internalization of beliefs, values, and moral principles (Furrow, King, \& White, 2004; King, 2008; Walker, \& Reimer, 2005), which in turn guides behavior and results in prosocial engagement (King, \& Furrow, 2004; Yates, \& Youniss, 1999) in youth. Several studies showed that more religious youth were significantly more likely to be involved in various forms of civic engagement than their less religious peers (e.g., Crystal, \& DeBell, 2002; Serow, \& Dreyden, 1990). Living out religious beliefs and values (i.e., prosocial engagement) may contribute to one's sense of purpose (Furrow, et al., 2004; Mariano, \& Damon, 2008).

The embodiment of (or living out) religious values is often viewed in terms of spirituality. Spirituality is defined as "a personal quest for understanding answers to ultimate questions about life, about meaning, and about relationship to the sacred or transcendent, which may (or may not) lead to or arise from the development of religious rituals and the formation of community" (Koenig, et al., 2001, p. 18). Mariano and Damon (2008) suggested that spirituality may guide youth towards contribution by providing a sense of purpose depending upon the salience of faith in their lives. Their model suggests that through exploring the importance of religious convictions to youth we may be able to more fully understand the relationship between religion and purpose.

\section{The Current Study}

This study aims to build upon a recent qualitative study conducted by King and colleagues (2014), which found that fidelity was central to adolescents' descriptions of experiences of spirituality and religion. In their study, youth participants were nominated for living with a profound sense of spirituality in their diverse culture and communities (i.e., spiritual exemplars). They reflected upon their belief system, including how they made sense of the world and what was important to them, and also expressed devotion to their espoused beliefs. In addition to talking about the centrality of their faith, the exemplars also described having a strong sense of purpose. However, King and colleagues focused on identifying aspects of spiritual development, rather than specific roles of fidelity and purpose. Given the prominence of ideological commitments in fidelity, its presence in religion, and proposed role in purpose, the current study proposes that fidelity may be helpful in explaining the relationship between religion/spirituality and purpose among adolescents. Thus, the current study aims to explore purpose and the presence of fidelity in this group of spiritual exemplars in order to further an understanding of the relationship between religion and purpose.

\section{Method}

Building on the existing exemplar study, consensual qualitative research (CQR) strategies (Hill, Thompson, \& Williams, 1997) were used to explore the concept of fidelity in a diverse sample of religious youth (King, et al., 2014). Given CQR's rigorous and structured analytic strategies that have been demonstrated to be effective to study participants' experiences and perspectives of less understood psychological phenomenon (Hill, et al., 1997), the method was employed to investigate the frequency of purpose and the nature of fidelity in this sample.

\section{Participants}

The sample $(\mathrm{N}=30)$ was an international group of adolescents with ages ranging from 12 to 21 (12 females, age $M=17.73$ ). The countries of origin represented in this study included the 
following: India (6), Jordan (2), Kenya (6), Peru (4), the United Kingdom (6), and the United States of America (6). Although most of the participants spoke English, some spoke Spanish, Arabic, and Hindi. Twenty-nine of the 30 participants affiliated with a religion including Buddhism (1), Hinduism (3), Judaism (1), Islam (6), Christianity (Protestant =12, Roman Catholic = 4), Sikhism (1), and mixed-religion (1). The nonaffiliated participant was a selfdescribed atheist from Northern Ireland.

\section{Instrument}

The original research team developed the interview protocol utilizing current research and expert contributions in order to create a semi-structured interview that inquired into areas relevant to spirituality, religion, purpose, and life goals. For a full description of the protocol and its development see King, et al. (2014). Specifically, participants were asked about personal experiences and perspectives on (a) identity, (b) spirituality and religion, (c) morality, (d) major life experiences, (e) people of influence, and (f) purpose.

\section{Procedures}

As documented in King et al. (2014), the participants were recruited through an extensive nomination process using a snowball method. The original team obtained 50 exemplar nominations from 17 nominators. Having reviewed each potential exemplar, the research team selected 32 adolescents based on gender, age, socio-economic status, and spiritual diversity. The exemplars participated in an interview lasting 2 to 3.5 hours; however, two transcripts were eliminated from analysis in order to maximize spiritual and geographic diversity. The research team conducted the interviews in person in the participants' hometowns, which were coordinated by a local research coordinator. All interviews were conducted and transcribed in English except for interviews occurring in Jordan and Peru. Interviews in Jordan were conducted in Arabic using spontaneous translation provided by a local translator. In Peru, an original research team member who was a native Spanish speaker conducted the interviews, which were subsequently translated into English.

\section{Current Research Team}

The research team for the current study included two females and one male. The principle investigator was a Caucasian male doctoral student in clinical psychology. A Caucasian female doctoral student in clinical psychology assisted in coding data and collaborated during the consensus process. A Caucasian female developmental scholar who has a Ph.D. in Marriage and Family Studies and M.Div. in theological studies served as an auditor in the data analysis.

\section{Data Analysis}

The data utilized in this study were portions of participants' transcripts previously coded in the original study that were judged to involve fidelity (see King, et al., 2014). Fidelity was chosen because of prior links of purpose and commitment which seemed to reflect fidelity more saliently than other elements of spiritual development (King, Carr, \& Boitor, 2011). These selected portions of data were further analyzed in order to identify the frequency of purpose and the nature of fidelity. Data analysis drew on procedures of CQR methods in order to identify themes and patterns from narrative data. Following CQR techniques (for a full description see Hill, et al., 1997), the general data analytic strategy included identifying domains or primary topic areas, and recognizing related core ideas within the transcripts that linked religion and purpose. The team met to discuss coding discrepancies until consensus occurred in each instance. Consensus was based upon reviewing the literatures definitions of each domain; then the team reassessed the discrepant codes. Transcripts were coded and data segments were assigned within each transcript to reflect the various domains using NVivo 5 as qualitative coding and analytic software. 


\title{
Results
}

The study investigated the presence of fidelity in these religious exemplars' lives as it might relate to purpose and religion. Throughout the several iterations of analyses, findings focused on general themes that emerged from items coded for fidelity from the transcripts. These prior iterations served as a broad starting point to explore the content of participants' fidelity. Each participant $(N=30)$ reported a sense of fidelity, albeit in different ways. Fidelity was expressed through: descriptions of worship experiences, career choices, relationships, and lifestyle preferences. For these unique young people, fidelity was found to be a whole-hearted sense of devotion that influenced their thoughts and guided behavior. Additionally, 29 of the exemplars reported purpose, which was reflected in a sense of strivings towards meaningful goals. The analysis yielded the following domains: beliefs $(n=29 ; 97 \%)$, values $(n=28 ; 93 \%)$, morals $(n=26 ; 87 \%)$, and resolute commitment $(n=25 ; 83 \%)$.

\section{Beliefs}

A central theme that emerged in all but one of the participants' interviews involved convictions about specific divine entities, principles, or ideas. The exemplar responses indicated ideological tenets concerning their understanding of the nature, character, or actions of God or a divine entity. We defined this category as beliefs because of the prevalence of the use of the term belief in the existing literature. As such, this category of beliefs included descriptions of divine or more existential matters from the exemplar's perspective. For example, a Hindu exemplar from India stated, "People are here...to make the world better."

\begin{abstract}
Values
Almost all (93\%) of the exemplars clearly described what was important to them. For example, they described their ideal character and important virtues. These character traits could be religious (e.g., holiness, righteousness, spiritual) or general (e.g., moral, trustworthy, kind). Many exemplars held certain virtues, such as honesty, integrity, and caring, to be in their character. We named this theme values as it described principles that were held in high regard by the exemplar. A participant from the United States who self-identified as Jewish and Humanist noted, "I do not want anything that creates a dependence for me, be it other people, alcohol, drugs, caffeine...I want to be a person others can count on and someone who cares about other people." This young person valued being authentic to himself and not having a dependence on other people or substances.
\end{abstract}

\section{Morals}

The exemplars $(\mathrm{N}=25)$ frequently spoke about "the right thing to do." These exemplars reported having appropriate and inappropriate behaviors due to their spiritual traditions. We coded these principles and ethics by which the participants distinguished between acceptable and unacceptable behavior as morals. They expressed a robust morality codified by various behaviors for sexual practices, relationships, justice, responsibility, and character. For example, one Buddhist exemplar from the United States suggested, "You're on earth. So now make do with what you have. So interact with society with these morals in mind."

\section{Resolute Commitment}

In exploring fidelity in the lives of the participants, the presence of resolute commitment emerged as a typical finding in the exemplars' interviews. The exemplars also articulated a sense of commitment to these worldviews $(N=25)$. The exemplars commonly expressed how their devotion informed and impacted each aspect of their lives. The poly-religious American 
exemplar articulated, "My spirituality motivates me to provide impassioned service, from a religion of compassion, not of compulsion. I take all that is a part of who I am and put it into a life of service work." These young people's clarity of and loyalty to their beliefs impacted the way they live in the world.

In sum, analysis of self-descriptions of religious youth gave insight into the nature of fidelity, emphasizing the presence of beliefs, values, morals, and a commitment to them in their lives.

\section{Purpose}

All but one of the exemplars $(N=29)$ mentioned statements describing their intention to pursue goals that give their lives meaning. Most often these statements were informed by their religious commitments and beliefs. It is important to note that often these statements were long on conviction, but they were sometimes short on specifics. For example, many spoke of wanting to glorify God, help others, or live intentionally; but not all articulated actual goals or means of achieving those desired ends. Throughout the transcripts the exemplars expressed personal goals, personal meaning, and having a sense of being motivated by their religion. For example, one Hindu exemplar from India said:

As a Hindu, I'd like to live a good life. I don't want the best of the things in life, because not necessarily the best of the things in life are the best for you. I have to strive for an ultimate satisfaction, and we are working for that.

The only exemplar who did not have a clear sense of purpose provided vague statements during the interview. This exemplar seemed to identify religion more as an academic interest rather than a purpose given entity. It was unclear the degree to which those values manifested in daily activities.

\section{Discussion}

In order to illuminate the relationship between religion and purpose, the current study explored fidelity in lives of adolescent spiritual exemplars. Analysis not only revealed the presence of purpose in their lives, but also revealed the centrality of ideological commitments, suggesting the presence of fidelity. Given that all but one exemplar described a sense of purpose, the study provides further evidence for the relationship between religion and purpose. Descriptions in the transcripts suggest that fidelity may be a helpful means of explaining the link between religiousness and a sense of purpose.

For these adolescents, their beliefs are apparent when they talk about their worldviews and when they describe themselves. Consistent with Erikson (1964), these adolescents appear to interpret the world through their religious narrative as they have searched for meaning, asked existential questions, and committed to a belief system, indicating they approach the world with ideological conviction. They are clear about what is important, what is right, what they should seek, and how they should act. In addition to their sense of certainty, they also have conviction about and devotion to these ideals. Their statements often reflect deep-seated religious ideological commitments that contribute to an enduring sense of purpose consistent with Mariano and Damon's (2008) models of religion and purpose.

Consistent with previous studies (Mariano, \& Damon, 2008; Mariano, Going, Schrock, \& Sweeting, 2011), the exemplars' fidelity demonstrated that being anchored in a religious tradition seemed to enable them to act in a meaningful, prosocial way in their communities. 
Most of these adolescents had specific purposes informed by their religious or spiritual commitments including: improving themselves, helping others, developing families, and being productive members of society. Indeed, their social relations, vocational aspirations, personal goals, values, and actions seemed to reflect their commitments to their religious and/or spiritual ideology across multiple domains of their lives and their general purpose in life (King et al., 2014; Mariano, \& Damon, 2008). Many of these exemplars reported a desire to be caring, generous, and responsible people - along with actions consistent with these intentions. For them, religious traditions were also moral frameworks that informed purpose.

In alignment with both Damon (2008) and Moran's (2009) suggestions that purpose provides a trajectory for youth, the presence of these values seemed to guide the exemplars towards behavior consistent with their religious tradition. Often this personal sense of purpose was attached to a future profession. Though we did not observe their behavior, the exemplars did report prosocial engagement consistent with their religious ideals (Furrow et al., 2004), as well as participation in civic activities (Yates, \& Youniss, 1999) and engagement in open dialogue with those with differing religious convictions. The values inherent within the religion seem to alter their developmental trajectory so it is conceivable that the type of the ideological content may guide behavior either in a pro- or antisocial direction.

Given the potential influence of fidelity in the lives of youth, youth workers may benefit from fostering fidelity in adolescents. Several religions and other organizations have socialization practices for their adherents. Through classes and rites of passages, youth may begin to learn about how their social group interacts in the world in a prosocial way. However, as the case of the outlier exemplar, to have a sense of purpose influenced by one's religious beliefs it is not simply an intellectual assent to certain tenets. It is something that is expressed through daily behaviors and interactions. As such, dialoguing with, mentoring, and living-life together may all be mechanisms that create a reflective posture about one's beliefs. These practices can also help ensure that a professed commitment is more than words, but is reflective of a heartfelt fidelity that moves a person to live out their life's purpose.

\section{Limitations}

Drawing on exemplar methods (see, Bronk, King, \& Matsuba, 2013), the data from this study was collected from a specialized sample of adolescents to gain insight into less understood domains of development. Although these exemplars are atypical of youth in regards to their spiritual commitments, they are typical in many other regards. Their experiences and perspectives were expected to provide rich and insightful data to increase an understanding of how religion and purpose connect, but we recognize that our findings are not descriptive of all people. Not all adolescents are able to articulate their beliefs or demonstrate ideological commitments through their actions as clearly as these exemplars. However, these young people provide a compelling example of how religion may provide opportunities for others to internalize ideology that informs a sense of identity and purpose.

Additionally, we acknowledge that the nomination procedures may have resulted in overlooking other forms or types of religious or spiritual youth despite a broad search approach. Further research may benefit from considering more normative or folk psychology approaches within specific populations (King, Mueller, \& Furrow, 2013). In addition, collaborative research teams that bridge developmental psychologists and indigenous or cultural psychologists would increase methodological sensitivity to specific developmental and cultural issues (Jensen, 2012). While we attempted to examine fidelity, purpose, and religion around the globe, more 
comparative studies are necessary to further understand the contribution of place and culture on spiritual development in larger samples.

\section{Future Directions}

Although our study provides an important step in illuminating the relationship between religion and purpose, important ground is still to be made. For example, it is important to explore the ethical nature of religious convictions and how they may shape one's sense of purpose. How does antisocial or exclusive religious ideology change the developmental trajectory of youth compared to youth with devotion to prosocial religious beliefs? In addition, the current study raises important issues regarding culture. Although all of the participants described general ideas about their purpose in life, it is important to question if purpose might be conceptualized differently in more individualistic cultures than it is in more collectivist cultures. Do adolescents in Western cultures express a sense of purpose in more personal or individualistic terms or goals? Do youth from more collectivist cultures express a more communal or generalized sense of purpose? How do religious beliefs and traditions mitigate the expressions and pursuits of purpose in different types of cultures?

Researchers and practitioners may benefit from recognizing the importance of ideological commitment in the lives of young people. Our findings suggest that for this unique set of adolescents, religious tradition is not merely a demographic checkmark - it is a way of life. To this end exploring the centrality of religion in a young person's life may yield a better understanding of things like life purpose rather than assuming all religious practice is the same.

\section{Conclusion}

The study suggests that for these unique spiritual exemplars fidelity was found to be a resolute commitment to a value system, which they internalized and in turned guided their actions. As such fidelity provides an important link for understanding the relationship between religion and purpose. Fidelity highlights the importance of ideological convictions and describes how commitments to religious beliefs may inform and shape a young person's sense of purpose in life. The exemplars' descriptions suggest that having beliefs alone are not adequate to shape purpose in action, but it is devotion and loyalty indicative of fidelity that may explain why ideology at times so deeply shapes young people's lives.

\section{References}

Bronk, K., Hill, P., Lapsley, D., Talib, T., \& Holmes, F. (2009). Purpose, hope, and life satisfaction in three age groups. The Journal of Positive Psychology, 4, 500-510.

Bronk, K.C., King, P.E, \& Matsuba, M.K. (2013). Introduction to exemplarity research. In Matsuba, M., King, P., Bronk, K. (Eds.), New Directions for Child and Adolescent Development: Exemplar Methods and Research: Quantitative and Qualitative Strategies for Investigation.

Côté, J.E., \& Levine, D. (2002). Identity formation, agency, and culture. Newark, NY: Lawrence Erlbaum Associates.

Crystal, D.S., \& DeBell, M. (2002). Sources of civic orientation among American youth: Trust, religious valuation, and attributions of responsibility. Political Psychology, 23, 113-132.

doi: $10.1111 / 0162-895 \times .00273$ 
Damon, W. (2008). The path to purpose. New York, NY: Simon and Schuster.

Damon, W., Menon, J., \& Bronk, K. (2003). The development of purpose during adolescence. Applied Developmental Sciences, 7, 119-127.

Damon, W., \& Hart, D. (1992). Social understanding, self-understanding, and morality. In M. Bornstein \& M.E. Lamb (Eds.), Developmental psychology: An advanced textbook (3rd ed., pp. 421-464). Hillsdale, NJ: Erlbaum.

Erikson, E. (1964). Insight and responsibility. New York, NY: W.W. Norton.

Furrow, J., King, P.E., \& White, K. (2004). Religion and positive youth development: Identity, meaning, and prosocial concerns. Applied Developmental Science, 8, 17-26.

Hill, C., Thompson, B., \& Williams, E. (1997). A guide to conducting consensual qualitative research. The Counseling Psychologist, 25, 517-572.

Jensen, L.A. (2012). Bridging developmental and cultural psychology: New syntheses in theory, research, and policy. Oxford University Press.

King, P.E. (2008). Spirituality as fertile ground for positive youth development. In R. Lerner, R. Roeser, \& E. Phelps (Eds.), Positive youth development and spirituality: From theory to research (pp. 55-73). West Conshohocken, PA: Templeton Foundation Press.

King, P.E., Carr, D., \& Boitor, C. (2011). Spirituality, religiosity, and youth thriving. In Behavior. Positive Youth Development: Research and Applications for Promoting Thriving in Adolescence. Amsterdam, Netherlands: Elsevier Press.

King, P.E., Clardy, C.E., \& Ramos, J.S. (2014). Adolescent Spiritual Exemplars Exploring Spirituality in the Lives of Diverse Youth. Journal of Adolescent Research, 29(2), 186-212.

King, P., \& Furrow, J. (2004). Religion as a resource for positive youth development: Religion, social capital, and moral outcomes. Developmental Psychology, 40.

King, P., Mueller, R., \& Furrow, J. (2013). Cultural and contextual considerations in exemplar research. In Matsuba, M., King, P., \& Bronk, K. (Eds.), New Directions for Child and Adolescent Development: Exemplar Methods and Research: Quantitative and Qualitative Strategies for Investigation (Special issue).

Koenig, H.G., McCullough, M.E., \& Larson, D.B. (2001). Handbook of religion and health. New York, NY: Oxford University Press.

Lerner, R., Dowling, E., \& Anderson, P. (2003). Positive youth development: Thriving as a basis of personhood and civil society. Applied Developmental Science, 7, 172-180.

Lerner, R.M., Roeser, R.W., \& Phelps, E. (Eds.). (2008). Positive youth development and spirituality: From theory to research. West Conshohocken, PA: Templeton Press.

Markstrom, C. (1999). Religious involvement and adolescent psychosocial development. Journal of Adolescence, 22, 205-221. 
Markstrom-Adams, C., Hofstra, G., \& Dougher, K. (1993). The ego-virtue of fidelity: A case for the study of religion and identity formation in adolescence. Journal of Youth and Adolescence, 23, 453-469.

Mariano, J.M., Going, J., Schrock, K., \& Sweeting, K. (2011). Youth purpose and perceived social supports among ethnic minority middle school girls. Journal of Youth Studies, 14, 921.

Mariano, J.M., \& Damon, W. (2008). The role of religious faith and spirituality in the development of purpose in adolescence. In R. Lerner, R. Roeser, \& E. Phelps (Eds.). Positive youth development and spirituality: From theory to research. West Conshohocken, PA: Templeton Foundation Press. pp. 210-230.

Moran, S. (2009). Purpose: Giftedness in intrapersonal intelligence. High Ability Studies: Special Issue on Giftedness and Character, 20, 143-159.

Serow, R.C., \& Dreyden, J.I. (1990). Community service among college and university students: Individual and institutional relationships. Adolescence, 99, 553.

Walker, L., \& Reimer, K. (2005). The relationship between moral and spiritual development. In P. Benson, P. King, L. Wagener, \& E. Roehlkepartain (Eds.). The Handbook of Spiritual Development in Childhood and Adolescence (pp. 265-301). Newbury Park, CA: Sage.

Yates, M., \& Youniss, J. (1999). Roots of civic identity: international perspectives on community service and activism in youth. New York, NY: Cambridge University Press.

(C) Copyright of Journal of Youth Development Bridging Research and Practice. Content may not be copied or emailed to multiple sites or posted to a listserv without copyright holder's express written permission. Contact Editor at: patricia.dawson@oregonstate.edu for details. However, users may print, download or email articles for individual use.

ISSN 2325-4009 (Print); ISSN 2325-4017 (Online) 